\title{
VIOLENCIA DE GÉNERO, CUSTODIA COMPARTIDA Y MEDIACIÓN FAMILIAR EN ESPAÑA. DISCURSOS PROFESIONALES
}

\author{
GENDER-BASED VIOLENCE, JOINT CUSTODY AND FAMILY MEDIATION \\ IN SPAIN. A STUDY ON PROFESSIONAL SPEECH
}

\author{
Francisco Gómez Gómez \\ Universidad Nacional de Educación a Distancia UNED, Madrid / España \\ fgomezg@der.uned.es \\ https://orcid.org/0000-0001-7543-9104 \\ Raúl Soto Esteban \\ Universidad Complutense, Madrid / España \\ rasoto01@ucm.es \\ https://orcid.org/0000-0002-0639-5934
}

Recibido/Received: 30/01/2020

Modificado/Modified: 12/05/2020

Aceptado/Accepted: 15/06/2020

\section{RESUMEN}

Los profesionales de los juzgados de familia entre ellos jueces y trabajadores sociales actúan en las familias con diferentes relaciones interpersonales conflictivas. Estos profesionales abordan la violencia de género, la custodia compartida y la mediación familiar en su práctica profesional diaria. Este artículo, basado en una investigación doctoral más amplia sobre el trabajo social judicial como ayuda en las crisis conyugales, analiza cualitativamente los discursos obtenidos en entrevistas realizadas a jueces y trabajadores sociales de los juzgados de familia de Madrid y Barcelona. Se reflejan las opiniones más citadas en la actuación pericial y judicial, realizando una prospección anónima para alcanzar la expresión libre de los profesionales. Los resultados ofrecidos indican que se debe continuar investigando los problemas que se presentan en los Tribunales de Familia, intentando no polarizar el pensamiento sobre temas que son importantes para la organización de las familias en crisis.

\section{PALABRAS CLAVE}

Género; violencia; custodia; familia; juzgados.

\section{SUMARIO}

1. Introducción. 2. Metodología. 3. Análisis. 3.1. La custodia compartida. 3.2. La violencia de género. 3.3. La mediación familiar. 4. Conclusiones. 5. Índice de citas. Bibliografía.

\section{ABSTRACT}

Judges and social workers developing their professional activity in the family courts, deal with several troubled relationships that appear in families, including the gender-based violence, the joint custody and family mediation. This article, based on a doctoral thesis about how judicial social work assist with the processes occurred in marital crises. It analyses qualitatively the discourses obtained in interviews with judges and social workers in the Family Courts of Madrid and Barcelona. The study reflects the
} 
most cited opinions of professionals of expert and legal action by an anonymous research to achieve the free expression of professionals. The results offered indicate the need to continue investigating the issues addressed in Family Courts, rather than continuing to polarize thinking on issues that are significant for the organization of families in crisis.

\section{KEYWORDS}

Gender-based; Violence; Custody; Family; Courts.

\section{CONTENTS}

1. Introduction. 2. Methodology. 3. Data analysis. 3.1. The joint custody. 3.2. The gender-based violence. 3.3. The family mediation. 4. Conclusions. 5. Index of quotations. References.

\section{INTRODUCCIÓN}

La relación entre los trabajadores sociales judiciales y los jueces de familia se produce en un ámbito laboral en el cual los conflictos familiares dificultan la resolución de las separaciones y divorcios (Gómez y Soto, 2015). La nueva organización familiar tras la crisis se inicia con el auto del juez, ayudado por la propuesta de los trabajadores sociales judiciales, y en este documento judicial se acuerdan las medidas mediante las cuales se realizará el cuidado de los hijos menores de edad.

La violencia de género se define en la Ley Orgánica 1/2004 de Medidas de Protección Integral Contra la Violencia de Género como "todo acto de violencia física y psicológica incluidas las agresiones a la libertad sexual, las amenazas, las coacciones o la privación arbitraria de libertad". Estos actos regulados en la ley se dan por el hombre sobre la mujer dentro de una relación de pareja o una vez finalizada ésta. Es un problema que en principio queda fuera de los juzgados de familia ya que desde el año 2004 es competencia de los Juzgados de Violencia sobre la Mujer. Es evidente que la violencia contra la mujer (al igual que otro tipo de violencias dentro de la familia) afecta a cualquier procedimiento judicial en curso y a la vida familiar, y cuando se produce la denuncia se inicia una crisis que modifica la organización y dinámica familiar, ya que se rompe la dinámica del sistema familiar. Lo que sucede a partir de ese momento supone una gran incertidumbre para los miembros de la familia, por ello Perrone, R. y Nannini, M. (1997: 20) indican la dirección del trabajo a realizar, pues la violencia no es un fenómeno individual sino interaccional y en dicho contexto relacional los implicados en una interacción violenta han de responsabilizarse de su seguridad personal. Por lo cual, tanto las opiniones como la experiencia suelen confluir en un punto: que la intervención de la ley es necesaria, pero no suficiente. Pues la lógica de la exclusión dio cabida a una lógica de integración y negociación, según la cual la familia puede funcionar como una unidad de comprensión y de solución de los fenómenos de violencia, justamente porque es allí donde ésta tiene más posibilidades de surgir y, por ello, de abordarse y solucionarse.

La custodia compartida es un tipo de organización familiar en el cual los dos padres (o progenitores) mantienen igual o similar responsabilidad en el cuidado y crianza de sus hijos. Según Simón, M. (2010: 194): "El eje central de la custodia compartida o conjunta tras una separación o divorcio es la idea de coparentalidad. Es decir, que ambos progenitores participen responsablemente en el proceso de crianza de sus hijos."

Ruiz Callado y Alcázar (2017: 29) describen la evolución legal de la custodia compartida, de la siguiente forma: 
Entre los años 2005 y 2010 el modo de acceso al régimen de custodia compartida exigía el acuerdo entre las partes. Por este motivo, su tramitación se realizaba casi exclusivamente por la vía del mutuo acuerdo y no entraba dentro de la custodia disputada. En consecuencia, las resoluciones judiciales reflejaban el acuerdo entre las partes, pero el tribunal no se pronunciaba sobre la procedencia o viabilidad del régimen de custodia compartida.

Posteriormente, entre los años 2011 y 2012, se llevaron a cabo reformas legislativas, por parte de algunas regiones o comunidades autónomas españolas con competencia en la regulación de las relaciones paterno-filiales, con un denominador común: cambio en la terminología que regula las relaciones paterno-filiales y flexibilización del acceso a un modelo de custodia compartida tras la ruptura familiar.

El colectivo de padres separados considera que debe ser la medida que por defecto se adopte, ya que supone la igualdad de ambos padres ante el derecho y la obligación del cuidado de los hijos. Por otro lado, existen colectivos feministas (Themis, 2015) que plantean que los padres maltratadores desean este tipo de organización familiar para continuar con el maltrato tras la separación y apuntan en sus conclusiones sobre esta cuestión (Themis, 2015: 5):

El cumplimiento de la condena por violencia hacia la madre y/o hijos e hijas no puede ser causa para poder acceder a una custodia compartida.

No se pueden establecer regímenes, de estancia y de comunicación, tan amplios a los investigados o condenados por violencia, que se convierta de hecho, en una guarda y custodia compartida encubierta, como viene ocurriendo actualmente.

En esta cuestión, Bodelón (2010) analiza desde una perspectiva de género la legislación civil sobre custodia compartida a nivel estatal y autonómico, y critica las interpretaciones que se hacen sobre el alcance de la mediación familiar y sobre la invisibilización de la violencia de género. La tesis de Bodelón (2010) es que: "nuestra legislación civil está construyendo un discurso, aparentemente neutral, sobre la custodia compartida y la mediación que ignora o reduce las implicaciones de las violencias hacia las mujeres. El establecimiento de la custodia compartida como criterio prioritario, incluso en los casos en los que no hay acuerdo entre las partes, es una idea relativamente nueva en el ordenamiento jurídico español “(p. 132). La segunda parte de su argumento (Bodelón, 2010) es que la custodia compartida impuesta favorece el ocultamiento de la violencia de genero.

Por otro lado, hay quién plantea que la igualdad del hombre y la mujer pasa por la corresponsabilidad en el ejercicio del cuidado y educación de los niños, y por ello ven adecuada la forma de organización de la custodia compartida. La socióloga francesa Evelyn Sullerot (1993: 365) denunciaba en los años noventa la postergación del padre y planteaba una curiosa encuesta a adolescentes, que serían padres en el inicio del siglo XXI, en la que les preguntaba sobre esta cuestión y concluía su ensayo con esta afirmación:

Los chicos de quince años que se proyectan en esta paternidad cálida y activa no parecen tener idea de las trampas que han puesto en su futuro camino las leyes, las costumbres y los recientes prejuicios antipadres. (...) Las chicas que serán sus compañeras han comprendido perfectamente que no constituirá una derrota para las madres el hecho de reconocerle al padre el puesto y el papel que merece y el de garantizarle la permanencia de los vínculos que le unen con su hijo. Por el contrario, será el feliz corolario de la lucha de las mujeres por la igualdad y la garantía de las madres contra la soledad.

Las sentencias del Tribunal Supremo sobre la custodia compartida concretan en qué forma se adoptan las medidas de acuerdo al "interés superior del menor" y cuándo éste 
interés está afectado negativamente y hay que protegerlo:

a) Recogido en STS 257/2013 de 29 de abril, conclusión tercera: "Se declara como doctrina jurisprudencial que la interpretación de los artículos 92,5, 6 y 7 Código Civil, debe estar fundada en el interés de los menores que van a quedar afectados por la medida que se deba tomar, que se acordará cuando concurran criterios tales como la práctica anterior de los progenitores en sus relaciones con el menor y sus aptitudes personales; los deseos manifestados por los menores competentes; el número de hijos; el cumplimiento por parte de los progenitores de sus deberes en relación con los hijos y el respeto mutuo en sus relaciones personales; el resultado de los informes exigidos legalmente, $\mathrm{y}$, en definitiva, cualquier otro que permita a los menores una vida adecuada, aunque en la práctica pueda ser más compleja que la que se lleva a cabo cuando los progenitores conviven. Señalando que la redacción del artículo 92 no permite concluir que se trate de una medida excepcional, sino que al contrario, habrá de considerarse normal e incluso deseable, porque permite que sea efectivo el derecho que los hijos tienen a relacionarse con ambos progenitores, aun en situaciones de crisis, siempre que ello sea posible y en tanto en cuanto lo sea."

Tratando de articular dicho interés como el regulador principal del conflicto que se pretende solucionar entre ambos padres enfrentados en la separación conyugal, en un intento de trascender el mismo y que ambos de ocupen del cuidado de los hijos e hijas, poniendo el mismo por delante de sus disputas y desacuerdos.

b) Recogido en STS 533/2019 de 10/07/2019. La razón se encuentra en que "el fin último de la norma es la elección del régimen de custodia que más favorable resulte para el menor, en interés de este (STS 27 de abril 2012, citada en la STS 370/2013).”

c) Recogido en Auto 533/2019 del TS de fecha 10/7/2019. Como ejemplo de decisiones del tribunal supremo cuando ese interés del menor no se respeta y es necesario su protección por razones de violencia de género: "En atención al interés del menor, queda justificada la necesidad de privación de la patria potestad respecto del recurrente, que se encontraba ya en prisión en el momento de adoptarse esta medida, situación que se va a prolongar, ya que ha sido condenado por sentencia dictada el 31 de marzo de 2015 por la Audiencia Provincial de Madrid (sección 27 ) a diversas penas de prisión que superan los quince años por diversos delitos de violencia de género (homicidio en grado de tentativa, maltrato, quebrantamiento de medida cautelar, amenazas graves y leves, tenencia ilícita de armas, maltrato habitual y falsedad en documento oficial)."

En definitiva, todas las citas anteriores reflejan lo que las sentencias pretenden afrontar y solucionar, sin mucho éxito en los casos de mayor conflictividad, que en definitiva son los que llegan y perduran en el ámbito judicial estudiado.

Los criterios del tribunal supremo interesan lógicamente a la actuación pericial en los juzgados de familia, pero es preciso conocer también los técnicos, ya que el Tribunal Supremo sitúa en un bucle a los equipos psicosociales, o en un laberinto que ya apuntaba Ibáñez-Valverde (2004) antes de estas sentencias. Así, Ruiz Callado y Alcázar (2017b: 111), destacando los criterios apuntados por Ramírez (2003), destacan aquellos más relevantes que los jueces y expertos tienen en cuenta para la torna de decisiones sobre custodia en España. Todos ellos, tornados de uno en uno, resultan cuestionables para la recomendación de un sistema de custodia, por lo que se sugiere su valoración conjunta. Entre estos factores se destaca: cuidador primario, preferencias en los niños, acceso al otro progenitor, continuidad de la vida familiar, ajuste familiar, estado emocional y ajuste 
psicológico de los padres, edad de los niños, no separación de los hermanos, infraestructura y nivel de conflicto familiar.

La mediación familiar es una disciplina que se ocupa de procurar acuerdos entre los padres y madres que se separan. Los mediadores familiares son profesionales de distintas disciplinas (trabajadores sociales, psicólogos, abogados...) que reciben una formación específica como mediadores y a través de distintas sesiones con ambos padres les ayudan a acordar la organización familiar futura. Esta organización puede ser cualquier tipo de custodia y régimen de visitas, u otro sistema de gestión familiar. Desde distintos colectivos feministas (Themis, 2015) se considera que la mediación familiar está contraindicada en casos de violencia de género y la Ley Orgánica 1/2004 de Medidas de Protección Integral Contra la Violencia de Género en su artículo 44.5 así lo recoge cuando tras describir los asuntos que son competencia de los Juzgados de Violencia Sobre la Mujer, termina: "En todos estos casos está vedada la mediación."

Así, en este artículo se quiere dar a conocer los resultados obtenidos mediante las entrevistas realizadas a jueces y trabajadores sociales de los Juzgados de Violencia sobre la Mujer (anteriores Juzgados de familia) de Madrid y Barcelona sobre las relevantes temáticas estudiadas: Violencia de Genero, Custodia Compartida y Mediación Familiar

\section{METODOLOGÍA}

Este trabajo es parte de una investigación doctoral cuya primera fase se desarrolla a través de técnicas cualitativas. Se realizan entrevistas en profundidad a jueces de familia y trabajadores sociales judiciales de Madrid y Barcelona, y se les pregunta sobre la labor del trabajador social en la gestión de la violencia de género, la custodia compartida y la mediación familiar.

El resultado es la creación de una serie de discursos profesionales supone una aportación más objetiva sobre estas cuestiones en conflicto. Las entrevistas se realizan de forma anónima para conseguir un discurso más espontáneo y libre, se conoce la profesión de la persona que desarrolla el discurso ( $\mathrm{J}=$ Jueces y $\mathrm{TS}=$ Trabajador/a Social) y su procedencia ( $M=$ Madrid y $B=$ Barcelona), su lugar de trabajo. Las entrevistas se realizan a cuatro trabajadores sociales de juzgados de familia de Barcelona y a seis de Madrid y a cuatro jueces con competencias de familia de cada ciudad. Las variables estudiadas del universo mediante la muestra considerada (entre el 50\% de los trabajadores sociales de Barcelona y el $20 \%$ aproximadamente de los de Madrid) pueden considerarse suficientes para la significatividad del estudio realizado. No obstante, el dato de los jueces resulta más difícil de obtener por las competencias más integradas en los juzgados de la periferia.

\section{ANÁLISIS}

La investigación llega a un punto de concreción, en el que se pregunta a jueces y trabajadores sociales sobre varios temas importantes, objeto de trabajo en los equipos psicosociales, con la intención de evaluar la percepción de ayuda que tienen los jueces sobre el trabajo de los profesionales del trabajo social y la visión de la utilidad y trascendencia de estos trabajadores sociales. Los temas son:

1. Custodia compartida

2. Violencia de género 


\section{Mediación familiar}

\subsection{La custodia compartida}

La custodia compartida es un tema complejo en el que existe una polémica social importante que debe servir como contexto. Como ya se ha indicado anteriormente, hay asociaciones defensoras de la custodia compartida como punto de partida, como primera opción y más justa e igualitaria entre los padres. Por otro lado, hay asociaciones de ideología feminista que han denunciado esta posibilidad porque serviría para continuar con la relación de malos tratos del hombre a la mujer. La práctica habitual en los juzgados es que la concesión de la custodia implique la del domicilio conyugal, que con frecuencia es el único bien importante del matrimonio, y que lleva en muchos casos al progenitor no custodio a una situación económica precaria. La Ley 15/2005 modificó el artículo 92 del Código Civil e introdujo la aportación del equipo psicosocial para los supuestos contenciosos en los que se solicitase este tipo de organización familiar.

El artículo 233-9 del Código Civil catalán (Ley 25/2010 de 29 de julio, que constituye el Libro II del Código Civil de Cataluña, relativo a la persona y la familia), promueve la redacción de un Plan de Parentalidad, partiendo de la responsabilidad parental de ambos padres, no extinguida con el divorcio o separación matrimonial.

Los jueces responden considerando la aportación del trabajador social en estos supuestos. En el caso de los jueces de Barcelona hay una respuesta común de confianza en que el trabajador social y el equipo psicosocial puedan descubrir o evaluar con criterio si es una buena solución para la familia o no. Sin embargo, uno de los jueces describe con detalle la situación legal del problema, y resalta que en el tema polémico de la custodia compartida los equipos psicosociales suponen para el juez poder apreciar qué familia tiene delante y su problemática para considerar la custodia compartida en función de los vínculos familiares y las relaciones entre padres e hijos.

Aquí la experiencia de Cataluña, este acercamiento a los equipos psicosociales se ha reflejado en la legislación, no sé si lo conoces, en el nuevo código hay unas disposiciones adicionales en las que se establece la experiencia del trabajo realizado. Entonces en estas cuestiones polémicas, como la custodia compartida, es fundamental en dos sentidos: en primer lugar para que el juez pueda apreciar la familia que tiene delante, los vínculos que hay, la problemática social, la familia extensa, porque la custodia compartida tiene mucho que ver estas cosas, el grado de comunicación, la idoneidad de los hijos y los progenitores. (Cita de J1B)

La opinión técnica es valorada dentro de un campo complejo.

En los temas de custodia compartida, cada comunidad autónoma tiene su propia ley y a eso hay que atenerse, pero es muy importante la valoración del equipo psicosocial, porque al oír a las partes en un contexto más facilitador, averiguar el modo en que se han llevado a cabo las cosas durante el matrimonio o la relación de convivencia, o incluso cuando hay separaciones de hecho puede averiguarlo y en este punto, no es que se tiene que hacer un pronunciamiento como más o menos favorable, en el sentido de que pueda haber una presión mediática o social, sino lo mejor para los niños. (Cita de J4B)

Hay sospechas de que las peticiones de custodia compartida buscan anular la pensión compensatoria o solicitar la vivienda. En esto los trabajadores sociales pueden ayudar.

Pueden ayudar en ser una cabeza más a pensar en hasta que punto la petición es sincera. Es decir, con la sospecha de que se están pidiendo custodias compartidas totalmente coyunturales, y por tanto, separar el grano de la paja" (Cita de J3B) 
Pero la situación es incipiente en España y se considera que hay que estudiar los distintos casos para asegurarse de los resultados y no guiarse únicamente por prejuicios, y a la vez que se apunta a una histórica función del trabajador social en la justicia de familia, el seguimiento, por otro lado, se plantea la postura del Tribunal Supremo:

Todas estas medidas que se ven en la legislación sobre el ejercicio conjunto de la parentalidad ponen de manifiesto un nuevo campo de trabajo, que es el campo del seguimiento, del refuerzo de las medidas que se adoptan, y no sólo el seguimiento para que el juez compruebe que no se desvían, sino también para modificar determinadas conductas. Con la custodia compartida la tarea es esencial porque partimos de la base de que cuando en el juzgado se polemiza sobre la custodia compartida es que la relación no es buena. El Tribunal Supremo ya ha dicho que la relación no tiene por qué ser buena para que la custodia compartida se pueda implantar, que basta que sea viable. (Cita de J1B)

Hay un matiz en la forma de interpretar el acuerdo o desacuerdo entre los padres como criterio para acordar la custodia compartida. También se pide a los trabajadores sociales judiciales que controlen a las familias para luego declarar en caso de desacuerdo que padre ha sido el menos colaborador.

En este sentido se confunde muchas veces pues, los progenitores no tienen por qué llevarse bien, ni tomar café juntos. Tienen que tener esa mínima capacidad para hablarse, mandar un correo o ver un problema de salud de los hijos, y eso se puede dar de una u otra manera. Para eso los jueces y el equipo técnico tienen que hacer un trabajo conjunto. Aquí en la Audiencia Provincial estamos introduciendo en las sentencias una especie de recomendación en estas materias importantes, que los progenitores en el régimen de visitas deben colaborar, ser pacíficos en beneficio del menor y seguir las indicaciones del punto de encuentro, del trabajador social del servicio de atención a la familia, del equipo psicosocial, o mediador a que acudan. Hacemos la advertencia que este principio de colaboración, si no funcionará se tendrá en cuenta la actitud de colaborar para asignar la guarda individual a uno $u$ otro. Una especie de amenaza. (Cita de J1B)

Hay una crítica a los técnicos que han sido siempre reacios a aconsejar la custodia compartida sin acuerdo.

Aquí en Barcelona por los técnicos se ha adoptado una postura negativa cuando no había acuerdo y, sin embargo, hemos recibido un tirón de orejas por parte del Tribunal Supremo, que ha dicho: como con el derecho comparado en mediación, si no la impones obligatoria la gente no va. (Cita de J1B)

Es interesante el discurso de los jueces cuando hablan de la legislación en las distintas comunidades autónomas, y del desarrollo de la Ley de 2005, pues en su opinión expresan las disparidad de legisladores y leyes que suponen realidades diferentes en cuanto a las influencias políticas y sociales que les influyen, dando lugar a que la custodia compartida sea apreciada desde posiciones distintas y, con frecuencia, enfrentadas..

Hay dos legisladores, cinco legisladores ahora mismo, la Ley 15/2005, pero en Cataluña hay una ley diferente, en Aragón hay una ley diferente, en Valencia hay ley diferente, entonces el Legislador Español, el del Código Civil, territorio común, no es que se quedará a medio camino, porque el camino iba recorrido en un sentido positivo, lo que pasa es que fue cortocircuitado, lo que se trabajó en el Parlamento fue una cosa, y lo que en el último momento se introdujo con enmiendas, con parches, por presión de un movimiento feminista radical, que veía en la custodia compartida, lo que ve en la mediación y en otras cosas, un premio a los 
maltratadores. No cabe la custodia compartida con maltratadores, pero eso no significa que no se pueda trabajar en los casos que no haya maltrato, por muchas cosas. (Cita de J1B)

También se recoge como una evolución el camino que marca el "Código Civil de Cataluña" que en la línea de la Unión Europea no habla de custodia y visitas, sustituyendo términos antiguos y siguiendo el camino de retirar la culpabilidad y actuar de forma práctica. Pues la Ley Catalana recogía en el divorcio directamente el apartamiento de uno de los progenitores de la custodia de los hijos, lo que ha dado lugar a casos en los que los progenitores se llevan bien y solicitan la custodia compartida.

Es curioso, si ves la Ley Catalana no habla de custodia o visitas. Hablamos utilizando una terminología propia de cuando el divorcio era culpable. En el propio artículo 103 y 81, el progenitor apartado de los hijos. Partía de la base el legislador que cuando había un divorcio había que apartar de los hijos. Se podía escenificar con una mano que lo saca fuera de la familia, y se articula un régimen de visitas. $Y$ el término de custodia hace alusión al Ángel Custodio, y aquí hay que apelar a otras cosas, a la responsabilidad de las personas. Yo creo que, en Cataluña el Tribunal Superior dijo hace tres años que no era de aplicación el Código Civil, ni en cuanto al informe favorable del Fiscal ni en cuanto a la excepcionalidad, la experiencia que tenemos es positiva, la gente hace esfuerzos. En ese sentido la función pedagógica de la ley está dando sus frutos. Ahora mismo raro es el día que no tenemos dos o tres peticiones de custodia compartida, de gente que ha sido capaz de llevarse bien. Lo otro es el tema de la alienación parental. (Citas de J1B)

Los jueces de Madrid destacan la vinculación del asunto al informe pericial, algunos se sienten cómodos con esa ayuda y otros expresan sus dudas por la negativa de los equipos a proponer custodias compartidas en casos contenciosos, lo que sitúa a los jueces en el bucle ya descrito. Así en Madrid lo jueces intentan apoyarse en los equipos psicosociales, pero con ello se ven condicionados por los diferentes criterios que cada equipo profesional tiene en función de su adscripción a una posición en favor o en contra de la custodia compartida.

Ahora estamos vinculados por ley, si no hay un informe favorable. La sociedad no está concienciada de lo que es la custodia compartida. Desde ese punto de vista el asesoramiento que podéis hacer desde el equipo, puede incidir en que luego pueda llevarse a cabo. (Cita de $\mathrm{J} 1 \mathrm{M}$ )

Pues con la custodia compartida ayuda mucho, de hecho todos los que no vienen de mutuo acuerdo pasan por informe, porque es verdad que muchas veces en sala se discute la custodia compartida pero al final llegamos a un acuerdo, porque ellos se lo piensan mejor, porque la han pedido para presionar en otro sentido, porque se dan cuenta que es por los niños. Por la razón que sea, pero cuando el interés es real, pasan por informe porque necesitas conocer muchos datos de esa familia, porque los limites estrechos del juicio no te permiten llegar a tanta información. Casi todos esos pasan por el equipo psicosocial. (Cita de J4M)

Pero también se proponen cambios que superen el bucle tan comentado: padres que piden la custodia y el otro padre la niega y se refiere al conflicto con la seguridad que la custodia exclusiva le va a beneficiar. Se pide que se cambien los términos de custodia y visitas por el de reparto de tiempo; o que se empiece a valorar como articular las custodias compartidas, que se ofrezcan criterios generales.

En muchas Comunidades Autónomas con competencias en familia se va a poner la custodia compartida como criterio general. El problema es que la idea es no dar custodia compartida cuando hay enfrentamiento. Como ya saben que el criterio del 
equipo es que no hay custodia compartida si hay enfrentamiento, provocan el enfrentamiento. En el momento que se establezca como regla general, vamos a tener que ir a otros argumentos. (Cita de $\mathrm{J} 2 \mathrm{M}$ )

Las jueces ven una paradoja en que los movimientos feministas no deseen la implicación mayor del padre en la coeducación.

Es contradictorio, las propias mujeres deberían ceder las custodias. Que los eduquen los padres, que los niños tienen derecho a ser educados por uno y por otro. (Cita de J2M)

Y añaden la confusión de términos entre custodia y patria potestad y la propuesta de cambiar los términos.

Aquí el problema es que se confunde y el que tiene la custodia hace y deshace, se va lejísimos o cambia el colegio sin consultar. En el fondo confunden la custodia con la patria potestad. A lo mejor si cambiase la terminología. Y se hablase de tiempo compartido o de convivencia. (Cita de $\mathrm{J} 2 \mathrm{M}$ )

Otros lo ven función de un equipo mediador que habría que constituir y cuando se desarrolla este discurso hay una intención de controlar el desarrollo de la ejecución de la sentencia.

Vuestra labor no es de mediación, ahi está problema, vosotros hacéis el informe, analizáis y lo mandáis, luego para que una custodia compartida funcione, haría falta un equipo de mediación familiar, que no sois vosotros. (Cita de J3M)

También los jueces de Madrid critican la forma en que los técnicos están respondiendo a las solicitudes de informe sobre custodia compartida.

Pero yo creo que eso es una custodia compartida y que lo que habría que ver es si los padres, independientemente de su conflicto, quieren tener a los niños consigo, si tiene unas pautas educativas similares, en cuanto a normas de conducta, horarios, están de acuerdo en el colegio que lo llevan están de acuerdo a la formación religiosa o no, están de acuerdo en ir al cumpleaños de la abuela o no. Para mi podría funcionar. (Citas de J3M)

Y como los abogados conocen el mecanismo, muchas veces, aconsejan cómo boicotear la custodia compartida.

Claro, pero sabes lo que pasa, los abogados saben que si la madre dice que no a la custodia compartida, no se informa favorablemente a una custodia compartida, le dicen tú di que no, porque los psicólogos no van a informar. (Citas de $\mathrm{J} 3 \mathrm{M}$ )

Las legislaciones autonómicas sobre custodia compartida van a impulsar el cambio de esta dinámica según los jueces.

$Y$ hay comunidades autónomas que ya la han impuesto con legislación civil propia, como Aragón y Cataluña, ya lo tienen puesta como criterio principal. (Citas de J3M)

Los trabajadores sociales de Barcelona afrontan la cuestión de una forma constructiva. Plantean una situación de crisis en la que las viviendas no se pueden vender y creen que se debe hacer un esfuerzo profesional por acordar un sistema de custodia compartida, más allá de constatar y reseñar la falta de acuerdo. Las circunstancias sociales generales y particulares tienen que valorarse más allá de constatar que existe una falta de acuerdo entre los dos padres sobre la futura organización familiar.

Nosotros aquí ya la llamamos responsabilidad parental compartida porque nos han cambiado el nombre con la nueva Ley vigente desde el uno de enero de 2011. (Cita de TS1B)

La importancia de evaluar el lugar en el que residen las familias es otro ejemplo de 
criterios de evaluación propios del trabajador social y que a veces se olvidan.

Muchas veces nos olvidamos que son importantes cosas de este aspecto, como la situación geográfica, el sitio donde se mueve el menor. (Cita de TS2B)

Se añade que hay muchas maneras de definir y entender la custodia compartida. Hace falta un acuerdo para poder implementar organizaciones familiares que respondan a las necesidades de los hijos. La dinámica familiar se mezcla con la evaluación de la propia situación socioeconómica de la familia, la situación escolar de los hijos o los recursos que necesitan.

Entender la dinámica familiar que han tenido durante la convivencia, intentar asemejar lo de después. (Cita de TS3B)

La Ley Catalana obliga a realizar un plan de parentalidad. Lo que parece una buena idea, y seguramente lo sea, plantea dudas de inicio por la forma de llevarlo a cabo.

La ley la marca, aquí en Cataluña, por decreto, pues ya se establece; una vez que se separan hay que hacer un plan de parentalidad. (Cita de TS3B)

Es diferente en el caso de los trabajadores sociales judiciales de Madrid, hay profesionales que enfrentan el tema de forma constructiva, intentando llegar a acuerdos reales, y otros que se limitan a hacer una evaluación de la dinámica familiar. Se plantea si una custodia compartida puede ser un inicio, aunque se fuerce, al que la familia se adapte. Y hay profesionales que defienden el gestionar con los padres su alternativa, estudiarla y descender al nivel de la práctica.

Eso sí es un asunto de pura realidad porque una cosa es la solicitud y luego otra cosa es cuando te sientas con las personas que solicitan la custodia compartida a que la valoren, organizarla al día. Yo les digo: vamos a sentarnos, les hago un calendario de cada semana, con colores, los días que están con papá y otros que están con mamá, los intercambios. Y cuando lo ven tan real, es verdad que muchas veces nos dicen: bueno, claro lo podemos modificar, a veces son niños más pequeños. (Cita de TS1M)

La necesidad de evaluar una serie de variables, comunes a otras evaluaciones familiares.

Yo insisto en dar una visión de la realidad de la familia en ese momento concreto. (Cita de TS2M)

Los profesionales se hacen una pregunta al plantearles este tema: ¿Es una cuestión práctica o hay que valorar aspectos diferenciales o estilos educativos? Parece más razonable gestionar el nuevo mapa familiar desde las necesidades de los hijos y con los padres. Es un asunto sociofamiliar. Quizás sea más abstracto y menos útil evaluar estilos educativos o patologías.

Yo creo que sí, que es un tema muy importante porque para mí la custodia compartida no es un problema, ni un abordaje de conocimientos específicos de psicología, sino funcionales de la vida en relación. (Cita de TS3M)

Las dudas siguen siendo si es bueno para la familia proponer una custodia compartida cuando una de las partes se opone, aunque se reconozca que todo forma parte de una estrategia repetida. Luego depende de cómo se plantee el caso al profesional, si la custodia compartida es una novedad en la familia o se pide una revisión de una en curso.

¿Qué debe hacer un trabajador social judicial en un caso de custodia compartida? Depende de en qué formato venga esa custodia compartida: si es una propuesta, si es una revisión porque no está funcionando, o porque uno considera que no está funcionando. (Cita de TS4M)

Para evaluar eso, ver si el padre y la madre son aptos para seguir adelante. (Cita de TS5M) 
Hay otra aportación que partiría de una posición favorable para luego matizarla.

Yo soy pro custodia compartida. Creo que hay mucho desconocimiento, por parte de los jueces, porque hasta hace poco era algo impensable. Yo creo que siempre hay que dar custodia compartida. Parto en mis planteamientos de ver si es posible. (Cita de TS6M)

Las citas anteriores, de lo que opinan tanto jueces como trabajadores sociales, lo que desvelan son los conflictos no resueltos, los duelos que las separaciones no afrontadas, que al estar sin resolver, "como duelos congelados" condicionan las relaciones familiares entre progenitores e hijos e hijas. Mientras que los cónyuges separados no superen el duelo asumiendo y aceptando la situación creada por la separación, para así poder llegar a una nueva realidad más acorde con las necesidades de todos los miembros familiares, padres e hijos e hijas, las contiendas judiciales y sociales sólo suponen el consumo de energías que mantienen el estatus del problema, la homeostasis del sistema que es la resistencia al cambio. Que cada miembro en discordia acepte su propia situación como una realidad nueva y que pueda aprovecharla para su propio crecimiento y el de sus hijos e hijas es lo que influye en el bucle conflictivo y lo que jueces y trabajadores sociales desearían solucionar, pero en cambio se ven involucrados, con frecuencia, más en el conflicto que en la solución.

\subsection{La violencia de género}

La violencia de género es un tema complejo que afecta de forma grave a los núcleos familiares. La gestión judicial de estos conflictos va a ser determinante para la primera organización familiar tras la denuncia. La nueva Ley contra la violencia de género (Ley Orgánica 1/2004 de Medidas de Protección Integral Contra la Violencia de Género) crea el nuevo juzgado mixto (civil y penal) para la toma de decisiones integral en familias con este problema. Alguno de los jueces que responden a esta cuestión, la esquivan con el argumento de no ser de su competencia. Otros entran a valorar, desde la competencia o no, como esta situación ha influido en la forma de trabajar los conflictos familiares desde un juzgado, tanto desde la situación del juez como desde los profesionales.

En el caso de los jueces no hay una distinción clara en la visión de los profesionales de Barcelona y de Madrid. La cuestión es compleja y polémica y se valora que todas las denuncias de violencia de género se están trabajando de la misma forma, sin individualizar y particularizar cada caso y desde la perspectiva de castigar al denunciado, desde la visión del derecho penal. Esto influye en las realidades familiares. Se propone una visión de cada situación y una actuación preventiva y protectora de las personas afectadas, sin olvidar el castigo al responsable de conductas violentas, pero no priorizando éste. La complejidad de las situaciones familiares lleva a los juzgados a revertir los mapas de organización familiar, y donde existía una denuncia de violencia de género y una actuación penal inmediata, luego se han producido acuerdos o custodias compartidas o incluso custodias paternas.

Yo creo que los equipos deben hacer una tarea similar, habría que tener una formación buena en este ámbito. Aquí cuando hay violencia, lo primero que pasa es que hay que ver la entidad de esta violencia. Si quisiéramos trabajar esa violencia tendríamos que tener esa información, en este sentido, la mediadora y psicóloga Lisa Parkinson dice que hay muchos tipos de violencia y que necesitaríamos conocer la entidad y fortaleza personal de la mujer que sufre violencia, el origen de la violencia por parte del varón, si es ocasional, si es permanente, si se debe a drogas, alcohol, si se debe a una enfermedad mental, no siempre es por consecuencia del machismo, sino que muchas veces es por otra cosa. Muchas veces damos palos tremendos muchas veces inadecuados, que se vuelven atrás. Habría que trabajar si detrás de 
las agresiones que producen muertes en las mujeres hay comportamientos que son puramente de machismo, si no estamos reforzando algo, todo el mundo sabe que cuando uno está obcecado y le ponen una valla se salta la valla. Y podemos estar viviendo este fenómeno, de hecho aquí que veíamos también las apelaciones, en temas de violencia de género, nos sorprende que asuntos que nos vienen de violencia de género, o se impone la custodia compartida o se da la custodia al padre, y esto es sintomático. (Cita de J1B)

Se critica que sólo se puede opinar de una manera en este tema y que los discursos disidentes se arrinconan y critican ferozmente.

Lo que está claro es que cuando hay delito hay delito, y debemos aplicar la presunción de inocencia porque es la base del derecho penal. Cuando el asunto estaba en los juzgados civiles podíamos establecer medidas civiles para el tema de violencia, para prevenir situaciones de machismo, pero claro, ahora mismo no se puede, esto pasa a penal, y resulta que cuando el tema no es de penal, porque no es imputable, pues estamos fracasando, pero el legislador optó por esta vía y yo he escuchado la opinión de políticos en el sentido de hacer una revisión, pero lo que parece hasta ahora es que la revisión, ha sido muy curioso porque, se ha hecho desde el Senado y desde el Congreso y sólo invitan a personas que son del área o de la forma de pensar, o que se están favoreciendo sus despachos y demás, con el tema de la violencia doméstica. Todavía está por ver que se haga un estudio serio con profesionales que no opinen todos con el pensamiento único, respecto a tratar la violencia de género por la vía penal. (Cita de J1B)

La prioridad no debe ser castigar sino proteger y ayudar a las familias. Se considera que la opción del legislador no ha sido acertada y se justifican en la falta de apoyo a esta postura en el derecho comparado internacional.

De hecho ahí está el fracaso del intento de exportar nuestro modelos, salvo en Honduras y no sé si Colombia, que ha sido porque el Gobierno Español ha financiado proyectos, han puesto en marcha proyectos similares. En países europeos occidentales, este modelo no se ha seguido. Se criticó y en un curso que he estado en Inglaterra para jueces de familia es al contrario, la especialización es global, en el ámbito del derecho de familia, la cuestión es si va esto a tramitarse por la vía del delito es posterior, es cuando aparece un menor, un niño maltratado. Si hay un niño maltratado lo importante es que un juzgado con especialistas en la materia aparten a ese niño y se tomen medidas civiles, es secundario que se coja al maltratador y se le castigue, esto está en el orden de prioridades, aquí es que lo principal es juzgar el delito y condenar al culpable, la víctima... Aquí esta mentalidad es la que se pone de manifiesto, se puede proteger desde la jurisdicción a la mujer maltratada por otros muchos caminos y no solamente por el derecho penal. El derecho penal a veces por su propia naturaleza es irrealizable. (Cita de J1B)

Pero la cuestión más importante de este estudio es qué rol pueden ocupar los profesionales. Hay jueces que opinan que el equipo psicosocial hace una función de pacificación importante.

Pero esto que decías de la violencia, en la mayoría de los casos el hecho de exponer su problemática a dos personas en dos entrevistas, que lo hacen ellos, mitiga. No sé si estás de acuerdo, hablar y el otro te va retocando la información, en el mejor de los casos la gente no es mala persona y reflexiona, por eso la sola intervención del equipo psicosocial ayuda a mitigar el conflicto. (Cita de J2B)

Hay jueces que se ciñen a su función y derivan a los juzgados especialistas esta cuestión. 
Aunque existen muchos matices en la cuestión de la competencia que todavía hay que aclarar con la jurisprudencia o con reformas legales.

Nosotros no estamos especializados en violencia de género. Habría que preguntarlo al Juzgado de Violencia de Género. (Cita de J3B)

En un Juzgado de Familia no puede hablarse de violencia de género. Porque se mandaría al Juzgado de Violencia de Género. (Cita de J4B)

No queda claro, la Ley ha sido un quiero y no puedo, ha habido distintas interpretaciones jurisprudenciales: porque también si primero se formulaba la denuncia se pedían medidas de protección y luego se pedían las medidas civiles, aunque se había mandado a lo penal. El hecho de haber formulado una denuncia, no habría que andar con tantos detalles y darles más competencias. Incluso cuando afecta a menores, que se haya hecho esa delimitación si pega a mujeres sí, y los menores que son más sensibles. Son temas del legislador. (Cita de J1M)

\subsection{La mediación familiar}

No solo hay discrepancias respecto a la propia ley, también se pide mediación y nuevos recursos para atender la realidad familiar resultante de los episodios o denuncias de violencia de género. Se vuelve a recoger la opinión de que el derecho penal (el castigo) por sí mismo no resuelve la situación de conflicto familiar en estas situaciones familiares y que las denuncias inician una crisis que tiene consecuencias.

Puntual y que se justifica en una situación determinada, sí y a partir de ahí no se va a perdonar. No se van a establecer buenas relaciones que son imprescindibles para que funcione el núcleo familiar, aunque desaparezca ese núcleo, y se va a hacer mucho daño a los niños. Yo creo que no se debería fomentar la híper protección del denunciante y si mentalizarles que teniendo esa protección van a tener que tener vías de comunicación para sus hijos. Es una labor más social y de llevarles a la solución del problema. A veces, el rigor de la ley en la violencia de género es contrario con lo que vemos en la práctica. Es que el tema de violencia de género es un poco peligroso en los temas de familia. (Cita de $\mathrm{J} 2 \mathrm{M}$ )

Es importante para los jueces que se trabaje con la familia para la reinserción familiar, pues esta es una función más de equipo psicosocial; y en los juzgados de violencia sobre la mujer se pide la ayuda de los forenses y las clínicas psiquiátricas, según los jueces. También se reclama la mediación familiar para casos de violencia de género, cuestión que está vedada por ley.

Nosotros ahora vemos poco, porque nosotros lo mandamos al de violencia. Yo he sido juez de violencia casi tres años, en un juzgado, nosotros en civil en el momento que lo vemos lo derivamos al juzgado de violencia, pero ahí volvemos como siempre a la labor de mediación. Que los juzgados de periferia no contamos con servicios de mediación familiar, que sería interesante también en los supuestos de violencia, no me gusta distinguir en graves o menos graves, pero bueno si los hay supuestos más grave, supuestos de violencia más leves, como un insulto, no una violencia continuada. Desde vuestro punto de vista, yo no sé si vosotros, si se tira más de forenses o clínicas psiquiátricas, no se acude tanto al equipo social. Es importante el entorno, los apoyos familiares que a mí me parecen en los casos de casos de violencia me parece mиy importante el apoyo familiar, que pueda salir del entorno, la forma que se articulan las visitas en los casos de alejamiento. (Cita de $\mathrm{J} 3 \mathrm{M}$ )

Se recoge la situación de conductas violentas aisladas e integradas en el conflicto y los jueces reiteran que la labor del equipo psicosocial es totalmente necesaria. 
Con la nueva Ley ya sabes que en el momento que hay denuncia nos tenemos que inhibir. Pero a veces hay una situación violenta, que no va más allá de lo que el conflicto genera. Lógicamente el equipo en la adopción de las medidas tiene mucho que decir y nos va a ayudar. (Citas de J4M)

La violencia de género es un problema tan complejo y serio que es difícil analizarlo en profundidad en este estudio. Los trabajadores sociales que trabajan en asuntos de familia ven familias en las que este problema subyace, bien porque haya existido y ya se ha archivado o hayan prescrito las medidas tomadas, o no se haya denunciado; bien porque el trabajador social forma parte de un equipo psicosocial al que le llegan solicitudes de los juzgados con competencias en violencia de género.

Como cualquier otro problema, debe ser tratado con formación y criterios claros, según los profesionales, los cuales simplifican el objeto a evaluar en el asunto de familia: la organización y dinámica familiar y los recursos a utilizar para la nueva organización familiar. Es importante trabajar con la familia, con el concepto de familia, para ayudar a crear la nueva situación, el mapa tras la crisis.

Yo aquí creo que las valoraciones, es lo que decía de las dos variables con que trabajamos. Ofrecer datos al juez, es difícil porque cuando hay un procedimiento penal o de violencia, influye mucho en la situación familiar, porque si hay una orden de alejamiento, una salida del hogar, una crisis familiar, donde los miembros cambian el rol, y los encontramos aquí en plena eclosión de la crisis familiar. Es difícil, lo que si entiendo es facilitar, entender la situación, valorar la situación desde la perspectiva de los menores pero también ayudando a los adultos a ver dónde pueden ganar esas habilidades para llevar esta situación. (Cita de TS1B)

Además de trabajar con la familia, y desde esa perspectiva, hay que conocer los recursos del entorno y ayudar a que se activen para beneficiar a los padres y a los hijos en su nueva situación.

Supongo con el conocimiento que nosotros también tenemos de recursos, también tenemos una serie de recursos que pueden estar interviniendo en violencia familiar. Aqui el trabajador social aporta mucha experiencia, si tu conoces estos recursos, en la propia intervención ya estás derivando a la familia, llevándola hacia un camino que crees que es el que debe seguir, recursos que trabajen con la mamá con los niños, con el papá... aquí tenemos una fundación que trabaja muy bien a nivel individual pero desde la propia fundación (FAGI), no tiene a un niño en un sitio, a un papá en otro... El recurso está interviniendo con la propia familia. (Cita de TS1B)

La situación es compleja pero interesa profesionalmente resolver la nueva realidad familiar y eso lo vienen haciendo trabajadores sociales desde hace muchos años, conocer recursos para derivar y evaluar la situación para realizar una propuesta que ayude a los hijos.

Yo creo que la aportación del trabajador social aparte de tener un mayor conocimiento de la red de recursos que puede haber, para ver como encaminar esto, las posibilidades que puede tener esta familia, a ver vendría a, no sé cómo decirlo porque me viene lo mismo y no quiero repetirte. No nos iríamos al estrés postraumático, sino que nos iríamos al punto de las relaciones familiares y de salirnos de ese estudio que nos acapara mucho y quizás la visión desde la perspectiva social, es lo que viene a contribuir y a complementar la otra parte que es la valoración de estas situaciones. Lo que pasa es que aquí es que como estamos separados, el tema de la violencia se ciñe a lo que es crisis familiares, se ve como 
cualquier caso. Aquí sólo lo vemos para régimen de visitas y custodia, a pesar de que puede chocar pero sí que nos llegan situaciones de violencia, con lo cual la metodología va a ser la misma, pero teniendo en cuenta la problemática específica suya. Se sale un poco de lo que es la violencia desde el punto de vista de la psicología, y volverlo al terreno más social. No quiero repetirme pero... (Cita de TS2B)

Se introduce un tema polémico: el de evaluar qué tipo de violencia es la que actúa en la familia y cómo afecta a las relaciones y a la situación de sus miembros.

Yo creo que ver que ha sucedido, objetivar, porque violencia es muy amplio, puedes escuchar a una señora que el hecho de acompañar al ginecólogo es invasión de intimidad y es maltrato, hay que objetivar, de que hablamos y cuando se prueba, hay que ver la gravedad y ver en qué medida afecta a los hijos, desde el estilo de relaciones y como puede perjudicar al niño el cambio de estar con uno o con otro. En la prevención es importante ver el aprendizaje que hay para los hijos. Todos sabemos que hay violencia pero la utilización que se hace de ella es... (Cita de TS2B)

La situación familiar se valora con la dificultad que tiene pero con las técnicas habituales para casos de familia, pero hay dificultades que hacen que estas situaciones familiares sean más difíciles de evaluar y trabajar.

Aquí violencia de género lo valoran en penal. Nosotros sí que nos encontramos con algún caso que hay un procedimiento con denuncia penal de violencia. Ahí nos resulta dificultoso porque ves esta familia, ves posibilidades de trabajar conjuntamente, pero como está este procedimiento penal por en medio hay dificultades. Cuando hay una orden de alejamiento y la vivencia de la persona no es tanto, como en los juzgados se le da. Para mí son casos difíciles de trabajar porque mi propuesta técnica sería una, pero la tienes que hacer legal. Y siempre hay que cumplir la ley pero en estos casos más. Pero tú te das cuenta que la persona afectada no lo vive tan mal, o no lo vive tan mal y después de estar con determinado servicio, y en estos casos ves la dificultad que hay a veces de separar la conyugalidad de la parentalidad. Si ves que este padre puede ser fantástico con este niño, si hay este tema por medio, son casos complicados que necesitan tiempo. También se nos pide que en estos casos seamos más ágiles, estos casos me cuestan un poquito, me cuestan por lo que es y porque hay casos que llegan que dices yo no veo violencia por ninguna parte. (Cita de TS3B)

Como se puede trabajar con unos servicios muy específicos desde una visión familiar, sin excluir a ningún miembro de la familia.

Hay que trabajar cada caso individualmente y los servicios se crean para tratar a mujeres, y esas mujeres están dentro de una familia y esos niños están dentro de una familia. Yo creo que se debe trabajar desde otra perspectiva, entonces yo puedo ir a un servicio y explicar algo, pero puede ser cierto o no cierto y luego cuando tú ya dices, es alimentar eso y mantenerlo, son casos que me cuestan, me cuestan. (Cita de TS3B)

La familia y los recursos se repiten como competencia del trabajador social, también interesa ver la situación personal de cada padre y su actitud ante la relación del hijo con el otro padre. Todo hay que valorarlo y ayudar a la familia a llegar a acuerdos. Hay que comprobar la situación de los niños, a nivel personal pero también prevenir y situarlos en su lugar filial.

Cuando hay ese caso siempre ha habido mucho movimiento entre servicios. Es 
importante tener buena comunicación con otros profesionales. Porque a veces es complejo y el discurso que trae una persona que se ha posicionado como víctima, está instalado y es difícil escuchar algo distinto a lo que sabes que van a decir respecto al otro. Es importante escuchar a otros profesionales y poder hablar pero no posicionado, si es víctima o no: tenemos un grupo familiar, ha pasado por esta situación y poder debatir un poco. (...) Es importante hacer un abordaje, tratar de tener la visión global. Porque, luego el tema de los menores es un tema que a mí me preocupa mucho, porque como proteges. Y además cuando se vive esta situación, independientemente del grado de violencia o no que haya habido, todo ese proceso ya lo es. Una preocupación mía es procurar que los niños no participen de eso. Es realmente difícil. (Citas de TS3M)

Los trabajadores sociales además creen que es importante potenciar la autonomía de la mujer para que salga de su situación de víctima y gestione su propio futuro y el de su familia.

Yo creo que sí. Otra cosa es el proceso interno de la persona, como, pero lo que es el (...) transmitir cosas, de intentar que una persona no esté siempre instalada en el rol de víctima, porque no conduce a nada y cuando vemos a una persona ya está el proceso de separación, o separada con lo cual es una etapa que se abre. Cerrar, ayudar a cerrar una etapa, y ayudar a abrir otra. Ahí sí que tenemos tarea los trabajadores sociales. Y también en instituciones como los puntos de encuentro, en la comunicación, hay una tarea, no tanto en el proceso interno de la persona, en el tratamiento, si necesita un apoyo psicológico, de roles funcionales y de ayudar a continuar. El tema de la autonomía. Recuperar la autonomía. (Citas de TS3M)

La complejidad de estos conflictos familiares es ser capaz de ver con claridad cuál es la situación familiar, más allá de quién miente y quién dice la verdad, saber dónde se sitúa cada uno y como se puede proteger a los niños y restablecer las relaciones con ambos padres sin crearles problemas. Las denuncias de violencia de género provocan un cambio en la situación familiar, lo que necesitan los padres y los hijos es readaptarse a la nueva situación y reanudar su vida y sus relaciones de la mejor forma posible.

Habrá que hacer un estudio de cómo está esa persona y ver si realmente hay violencia, porque realmente vemos aquí cada caso que nos pone los pelos de punta. No entendemos porque a una persona se la lleve a la cárcel o está dos noches en comisaría, porque otra persona se ha enfadado y dice que le ha pegado. $Y$ no es solamente un caso sino muchos. A mí me preocupa, es que esto se ha pasado al otro bando, lo desconozco porque no he hablado con compañeros. Y la verdad es que me agobia, porque no es un caso, es uno y otro. $Y$ te vienen diciendo, y vienen padres que no piden más porque van a ser denunciados. Esto ya me deja más que preocupada, piensas si usted podría tirar para adelante con su hijo y te dicen es que me ha puesto una denuncia y no sabes si es el padre o es que conoce este mundillo y dice para estar en la cárcel mejor... (Cita de TS5M)

Los casos dudosos y fronterizos, en los cuales no hay una situación clara y evidente de violencia de género, pero se denuncian conductas concretas, las cuales pueden haber surgido durante el conflicto, pero no ser crónicas de la convivencia. Estos supuestos son más difíciles de diagnosticar y trabajar en los juzgados.

El último de los temas planteados a jueces y trabajadores sociales judiciales es el de la mediación familiar. La intención de incluir estos temas en las entrevistas con estos profesionales es la de descubrir de forma práctica, con ejemplos claros, la situación de la disciplina en distintos escenarios. La mediación familiar la explican de diferente forma los 
jueces de Madrid y Barcelona: en Madrid hay una situación más precaria ya que la presencia de un equipo de mediación en los procedimientos judiciales depende de que exista acuerdo con el ayuntamiento correspondiente y lo dote. Así sucede en el de Madrid capital, pero no en todos los municipios de la periferia. En el caso de Barcelona existe el equipo de mediación con un técnico presente en la sede judicial. Respecto a la condición de trabajador social o no del mediador familiar, se desconoce en Barcelona ya que son técnicos mediadores para los jueces sin otra identificación. En el caso del municipio de Madrid, el convenio es con el colegio de abogados, por lo que ésta es su profesión, además de su necesaria cualificación como mediadores, lógicamente.

La tarea del trabajador social judicial puede ser de puente, de derivador a este servicio. Se apuntan problemas de aceptación, todavía las familias se muestran reticentes a aceptar este servicio. Los jueces si ven el rol del trabajador social judicial como útil en este campo:

Si al final nos ponemos con el tema de verlo... volvemos un poco a lo de antes, siempre nosotros le podemos sugerir acudir a todo esto, no se puede imponer, pero en estos temas que no son tan jurídicos, que afectan a temas personales, vosotros les podéis hablar, les recomendáis desde el punto de vista profesional que pues pueden ir de otra manera...y se pueden ir de otra manera. (Cita de J1M)

Regular. Ya tenemos el dispositivo funcionando, hemos hecho el protocolo, pero hay mucha rechazo todavía, ni siquiera cuando por parte del juzgado se les da cita para la mediación acuden a esa primera sesión informativa, ya les damos la cita y ni siquiera van. (Cita de J2M)

En la capital de Madrid el servicio ya está instaurado desde hace tiempo y los jueces explican su funcionamiento y la integración en los procedimientos.

La mediación como tal, sabes que tenemos un acuerdo con el ayuntamiento, entonces derivamos a las familias, hay unos equipos que vienen a la sede del juzgado para hacer aquí la sesión informativa, de manera que yo veo aquí un asunto que creo que es mediable, llamo al ayuntamiento y me dan día y hora. Entonces yo pongo una providencia para aquí abajo que tienen una sede para el equipo de mediación, van a esa sesión informativa y a partir de ahí me dicen si acuerdan o no acuerdan, me lo dice el propio ayuntamiento. Yo procuro no suspender, y si llegada la fecha de señalamiento siguen mediando, ellos me piden suspender, pero hay quién no quiere perder la fecha de señalamiento, la fecha de señalamiento sirve para poner fin a la mediación, no nos vamos a engañar. Pero también hay a quien le vale, a juicio vienen más pacificados y a veces con acuerdos parciales (Cita de J4M)

Hay jueces que requieren de los equipos psicosociales una función mediadora cuando realicen su función pericial, pero en general se conoce la diferencia entre las dos funciones y se apunta la sobrecarga de los equipos psicosociales y la necesaria división de funciones.

Yo creo que los equipos psicosociales son tan pocos y tienen tanto trabajo, que entonces la mediación además atribuírsela, desde el punto de vista económico es irrealizable. Pero no tendría que serlo, dentro de esos equipos auxiliares del juez debería haber equipos de mediación que no hicieran otra cosa, solo mediación. No es realizable a corto plazo por la crisis económica, entonces los equipos psicosociales lo que han de hacer es trabajar la mediación desde otros puntos de vista: dar a conocer la mediación, a las partes cuando intervengan, aconsejar a los tribunales y al juez que en los casos en los que no hay problemas jurídicos, problemas conductuales, por el bien de los hijos sería factible intentar procesos de mediación, y por supuesto, para hacer las sesiones informativas, podrían ser programadores y derivadores hacia la mediación. Eso no significa que, en otros 
ámbitos, cuando exista esa posibilidad y el trabajador social esté formado en mediación pueda hacer mediaciones si tiene tiempo. Lo que pasa es que cuando aquí en Barcelona se empezó a hacer mediación y los mediadores estaban dentro de los equipos se hizo un protocolo para que el miembro del equipo psicosocial nunca interviniera informando. (Cita de J1B)

La legislación catalana recoge la forma de llevar a cabo las mediaciones dentro de los procedimientos judiciales de familia (art. 233-6 de la Ley 25/2010 de 29 de julio, que constituye el Libro II del Código Civil de Cataluña, relativo a la persona y la familia, publicado en el BOE de fecha 21 de agosto de 2010). Pero hay jueces que no lo ven claro, que refieren problemas por la forma en que está planteada.

Se ha hecho una apuesta por la mediación, tenemos un equipo de mediación, nosotros derivamos todos los asuntos a la mediación, tienen día y hora, gratuito, voluntario, para que usted vaya a entrevistarse con un mediador, también hay un mediador en el colegio de abogados, leí ayer que los notarios también van por la mediación; pero la forma de plantear la mediación ahora no sirve para nada, así de claro. No hay ni un solo caso, uno para ser exacto, que se me resuelva por mediación. Ojalá se resolvieran por mediación, pero las personas que llegan al procedimiento que no ha podido resolver la situación antes o solos, cuando llegan al procedimiento están tan enconados que necesitan explicar, entonces van a mediación y la mediadora les dice solo vamos a intentar mediar sobre el asunto del procedimiento, $y$ dice "es que me engañó con otra" y sale el tema de la infidelidad, $y$ claro dice no de ese tema no podemos hablar. (Cita de J2B)

Evidentemente, la mediación tiene ese pero, el conocimiento de cuestiones de calificación de determinados criterios, saber que se puede obtener en un procedimiento judicial desde el punto de vista, ya no digo la guarda y custodia, sino temas económicos. En última instancia es el juez, pero si hubiese unos parámetros, los mediadores tendrían instrumentos para decir, se puede llegar hasta aquí, para que vais a llegar a juicio, cuando no hay más remedio no hay más remedio, pero. Si se sabe lo que se puede conseguir porque hay unos parámetros pues esto sería muy útil a los mediadores. Eso es el problema que tiene la mediación. (Cita de J4B)

Los trabajadores sociales judiciales de Madrid y Barcelona destacan la mediación como el mejor instrumento para resolver conflictos familiares. Desde esa idea común, desarrollan la forma en que los equipos psicosociales pueden contribuir a ello, la mayor parte de las opiniones desde la prudencia, situando fuera de los equipos la responsabilidad principal, pero con la ayuda y la colaboración de estos equipos psicosociales a los equipos mediadores. En concreto respecto a la profesión de los trabajadores sociales, se destaca la histórica función del trabajo social familiar como gestor de conflictos. Hay un protocolo de derivación que evita que la mediación y el trabajo judicial o pericial coincidan.

Nosotros tenemos un protocolo con los responsables de mediación familiar. Entonces, cuando vemos que nos llega un asesoramiento y podemos parar el asesoramiento e iniciar un proceso de mediación, lo mandamos para que puedan resolver sus dificultades más, sin medidas judiciales por en medio. Nunca trabajamos paralelamente, si hay una familia que está en mediación y nos llega a nosotros, tenemos un respeto para que la familia termine el proceso, si llegan a un acuerdo perfecto y si no llegan a nosotros. El protocolo parte de esto, de priorizar que las familias puedan solucionar sus problemas desde el diálogo y no desde la intervención judicial. (Cita de TS1B)

Los trabajadores sociales opinan que la mediación es algo integrado en su profesión, en 
su rol a nivel social.

Yo creo que aquí podemos aportar muchos años de experiencia, me podría pegar con algunos psicólogos, cuando se dice lo de nuestra profesión es la que por trayectoria... yo quiero barrer para casa, los trabajadores sociales ha sido una profesión que..., hoy ahora se le ha puesto ese nombre, pero no deja de ser una práctica que se viene haciendo hace muchos años, de una manera diferente, con unas dinámica y ritmo diferente. Yo creo que por formación y por la trayectoria hasta la fecha, está como muy dispuesto a trabajar con conflictos familiares, siempre se nos ha enseñado a trabajar, o nuestra capacidad de trabajo ha sido en situaciones de conflicto y necesidad, con lo cual hemos desarrollado una serie de habilidades que son necesarias para gestionar eso, yo por eso soy una gran defensora de esto. (Cita de TS2B)

Desde este lugar del trabajador social judicial si es posible facilitar acuerdos y disminuir el conflicto.

No es el lugar adecuado, pero yo creo que todo lo que sea fomentar el acercamiento, si desde aquí se puede hacer. Yo creo que cuando se rompe el yo, yo. Todos defendemos en nombre de los hijos, cuando lo que defendemos es nuestro estatus, nombre en la familia... Yo creo que el tener en cuenta al otro y buscar acercamientos, sin ser mediación plena, tener en cuenta los temas económicos, aunque no podamos entrar en ellos, puede ser bueno, sin llamarlo mediación familiar. (Cita de TS2M)

Los profesionales van explicando que no se puede hacer mediación familiar desde el juzgado, pero siempre es necesario llegar a acuerdos puntuales, que son beneficiosos para el proceso y para la familia, es una visión que se alejaría de la pericial pura. La siguiente aportación recoge el lugar de la profesión en la mediación familiar en tono crítico.

La mediación familiar, yo creo que es interesante en principio que todos los asuntos que pudieran trabajarse con ese proceso, yo creo que es mucho más constructivo. Yo creo que el trabajador social ahí, tenemos una tarea, lo mismo que otros profesionales, pero si pienso que nos están ocupando el espacio, sobre todo los psicólogos y los abogados, incluso otros profesionales de otras áreas. (Cita de TS3M)

Hay una conciencia clara de que en el trabajo diario se usan técnicas de mediación y se buscan acuerdos y consenso, sin la pureza del proceso mediador. También se pide formación en este campo.

Aquí tenemos un dispositivo específico de mediación familiar al cual mandan a las familias normalmente antes de que se inicie el procedimiento. Yo la mediación familiar es la que te he comentado antes. En cuanto a que se pueda llevar a una propuesta al juez lo más consensuada con la familia. Desde el punto de vista de una observación, desde el momento que participamos de una observación participamos de esa situación. Entonces sí que hacemos mediación. (Cita de TS4M)

Puede aportar, un estudio de ver la situación como está e intentar mediar, intentar llegar a un acuerdo. Pero yo desde mi sitio, la mediación no la contemplo. (Cita de TS5M)

Un poco lo que te estaba comentando, a mí la mediación en la justicia me parece fundamental. $Y$ nosotros somos un poco los que podemos ser ese instrumento, colocar a las personas en la tesitura de que resuelvan el problema o lo arreglen los demás, porque vosotros conocéis mejor que nadie la situación que tenéis, y es lo mejor. La mediación es la salida, la justicia sino lleva muy mal camino, es 
fundamental, pero necesitamos formación para hacer una mediación adecuada, mediadores somos los trabajadores sociales, pero nos falta una formación para justicia. (Cita de TS6M)

\section{CONCLUSIONES}

Los jueces y trabajadores sociales judiciales refieren que la realidad de las familias en conflicto es más compleja que lo que las distintas leyes, que regulan la actuación judicial y técnica ante los temas propuestos, recogen. Se produce una crítica general a las leyes.

La custodia compartida se regula en la ley de reforma de la legislación civil en el año 2005. Luego en la práctica, a los jueces les resulta difícil acordarlas contra el criterio de los técnicos. Los técnicos mayoritariamente se pronuncian en contra si hay un conflicto familiar. En Cataluña, la ley autonómica prevé un Plan de Parentalidad común, por lo que la situación varía y se hace más flexible. Los jueces plantean que los trabajadores sociales judiciales les sirven para aclarar cómo es la familia, pero critican la negativa de los trabajadores sociales a proponer custodias compartidas en casos contenciosos.

Los trabajadores sociales judiciales defienden su rol en estos asuntos familiares y plantean evaluar estas situaciones familiares desde la realidad y acercándose a cuestiones de vida familiar concreta, a cada situación sociofamiliar, a cada proyecto.

La violencia de género es un asunto que afecta a las situaciones familiares: los jueces toman una actitud crítica ante la ley y sus efectos prácticos o derivan el asunto a otros juzgados ya que son jueces de familia. La crítica se dirige principalmente a la intención penal de la ley, la búsqueda del castigo, y su escasa preocupación por las situaciones familiares que subyacen a la resolución de un conflicto familiar desde la denuncia. Los trabajadores sociales judiciales insisten en el tratamiento global del problema y en la solución integral, sin exclusiones, para todos los miembros de la familia, en la medida de lo posible.

La mediación familiar se enfoca como una intención, un deseo, pero también como una disciplina con sus profesionales, cercana al trabajo social familiar, y que precisa de la colaboración de jueces y trabajadores sociales judiciales. En la medida que soluciona situaciones familiares es útil a la Administración de Justicia y a las familias.

\section{5. ÍNDICE DE CITAS}

Las citas son anónimas, pero se conoce la profesión y lugar de desempeño laboral de cada persona:

J1B es el primer juez/a de Barcelona que contesta a la entrevista y así sucesivamente.

J1M es el primer juez/a de Madrid que contesta a la entrevista y así sucesivamente.

TS1B es el primer trabajador/a social de Barcelona que contesta a la entrevista y así sucesivamente.

TS1M es el primer trabajador/a social de Madrid que contesta a la entrevista y así sucesivamente. 


\section{BIBLIOGRAFÍA}

Bodelón, E. (2010). La custodia compartida desde un análisis de género: Estrategias machistas para invisibilizar la violencia en las rupturas familiares. En Picantó, T. La custodia compartida a debate. (pp. 131-154) Madrid: Dykinson.

Gómez, F. y Soto, R. (2015). Nuevas tareas, nuevos lugares del trabajo social judicial en España. Revista Serviço Social \& Sociedade, 121, pp. 10-23.

Ibáñez-Valverde, Vicente (2004). El laberinto de la custodia compartida. Claroscuros de un solo nombre con varios significados (1 y II), "DF" Boletín de Derecho Familia, El Derecho (Editores), año 4, no 40 y 41, noviembre y diciembre de 2004, pp. 1-15, en www.psicojurix.com/pdf/ellaberinto.CC.pdf

Ley 15/2005 de 8 de julio, por la que se modifican el Código Civil y la Ley de Enjuiciamiento Civil en materia de separación y divorcio.

Ley 25/2010 de 29 de julio, que constituye el Libro II del Código Civil de Cataluña, relativo a la persona y la familia.

Ley Orgánica 1/2004 de Medidas de Protección Integral Contra la Violencia de Género.

Perrone, R. y Nannini, M. (1997). Violencia y abusos sexuales en la familia. Barcelona: Paidós.

Ramírez González, M. (2003). Cuando los padres se separan: alternativas de custodia para los hijos: [guía práctica], Madrid: Biblioteca Nueva.

Ruiz Callado, R. \& Alcázar, R. (2017a). "Custodia compartida y familias negociadoras: perfil sociodemográfico". Revista de Ciencias Sociales, (RCS),Vol. XXIII, No. 3, pp. 28-38.

Ruiz Callado, R. \& Alcázar, R. (2017b). Factores determinantes en la atribución de la custodia compartida. Un estudio sociológico en los Juzgados de Familia (109-124). En Becerril, D. \& Venegas, M. La custodia compartida en España. Madrid: Dykinson.

Simón, M. (2010). "Aportaciones del trabajo social a la pericial de familia". En Tapia, J. J. (Dir.): Custodia compartida y protección de menores. Madrid: Dykinson, pp. 175-210.

Soto Esteban, R. y Gómez Gómez, F. (2015). El trabajo social en el foro familiar. Un estudio comparado. Alemania: EAE.

Sullerot, E. (1993). El nuevo padre. Barcelona: Ediciones B.

Themis: (2015). Conclusiones finales de los Seminarios-talleres de la Asociación de Mujeres Juristas Themis, celebrados en Las Navas del Marqués (Ávila) los días 27 y 28 de noviembre de 2015: "Custodia compartida". En la Red: https://www.mujeresjuristasthemis.org/prensa/noticias/154conclusiones-finales-custodia-compartida (consulta el 28/10/2019).

\section{Breve currículo:}

\section{Francisco Gómez Gómez}

Doctor y Licenciado en Ciencias Políticas y Sociología. Diplomado en Trabajo Social. Profesor Titular de la UNED y de la UCM. Departamento de Servicios Sociales y Fundamentos Histórico- Jurídicos.

\section{Raúl Soto Esteban}

Trabajador Social de los Juzgados de Primera Instancia e Instrucción de Alcobendas (Madrid). Diplomado Universitario en Trabajo Social. Licenciado en Historia del Arte. Doctor en Trabajo Social por UCM. Profesor asociado del Departamento del Trabajo Social de la Universidad Complutense de Madrid. 